\title{
Indigenous knowledge for the benefit of all: can knowledge management principles be used effectively?
}

\author{
Andrew M. Kaniki \\ Information Studies, School of Human and Social Studies, University of Natal \\ Pietermaritzburg, South Africa \\ kaniki@nu.ac.za
}

M.E. Kutu Mphahlele

Information Studies, University of the North

Pietersburg, South Africa

kutum@unorth.ac.za

Received: 1 June 2002

\begin{abstract}
Indigenous knowledge is one form of knowledge; the other is scientific knowledge. Indigenous knowledge is local knowledge unique to a given culture or society. By its very nature, it is not generally viewed in the business sense as "capital". It has tended to be "exclusive", at times susceptible to suspicion and abuse. Knowledge management involves the processing and handling of intellectual capital within and between organisations and communities. It facilitates knowledge generation, sharing and reuse. This paper addresses the extent to which knowledge management methodologies and principles can be used to manage indigenous knowledge for the benefit of all.
\end{abstract}

\section{Introduction}

Some 32 years ago, Ronald G. Havelock alerted the scholarly community, and the world in general, to the emergence of a new field, the "science of knowledge utilisation". He explained that two main social forces had facilitated this emergence. The first was a knowledge explosion, itself having been enhanced by refined and streamlined methodologies of discovery, thus leading to a very large increase in scientific knowledge. Havelock (1969:1) observed that the increase in scientific knowledge "outstripped the retrieval capacity of a typical scholar, and as a result, traditional modes of knowledge organisation and transmission [were] constantly modified, streamlined and automated". The second social force had been the growing expectation on the part of industry, government leaders and the general public that most of the storehouses of scientific knowledge should be useful to society.

The amount of scientific knowledge produced in the last 30 years has multiplied, and continues to increase beyond what had been experienced prior to and during the science-of-knowledge-utilisation era of the 1960s. This has partly been due to the developments in information and communications technologies (ICTs), which have made knowledge production and exchange easier and further enhanced the methodologies of knowledge discovery. We have become increasingly aware and appreciative of knowledge production and utilisation for human development, rather than knowledge production for its own sake. We have also become more aware that knowledge and its related components, namely information and data, can and do affect productivity and human development. It has become increasingly clear, at least to some, that data, information - and particularly knowledge, if approp-riately utilised can enhance productivity and indeed development. The converse is also clear; that is, that a lack and/or inappropriate use of data, and of the related information and knowledge, can lead to poor decision making and generally impact negatively on productivity and development. The development of the accurate measurement of the impact of data, information and knowledge on productivity and development in general is, of course, one of the major areas of research and debate today.

The desire to use scientific knowledge appropriately and effectively for human development has enhanced the development and further refinement of method-ologies, principles and techniques for managing data, information and knowledge. We have developed and continue to refine methodologies for assessing and identifying information needs, and for measuring and evaluating information delivery systems and services. In recent years, there has been an emphasis on the development of what can be considered a holistic approach towards knowledge production and use through knowledge management, its theories, principles and practices. 
While the generation, growth and utilisation of scientific knowledge are seen as critical for human development, the "problem" of the knowledge explos-ion in general, and its management and effective utilisation in particular, has been exacerbated by the increased recognition of the equally important role that indigenous knowledge (IK) can and should play in the development of the wider local and global communities. Although IK has been with us since the beginning of humanity, it has, owing to its own "local" and "environmentally specific" definition as will be explained later, generally not been standardised, popularised or internationalised. It may well be that not all types of IK can, or should, necessarily be internationalised. The debate on this issue requires another forum and paper. Suffice it to say that issues related to the internationalisation and/or the impact of globalisation on IK systems are issues that this paper will attempt to address.

The rise of colonialism in Africa had a profoundly negative impact on IK. Colonialism, to a large extent, introduced communities to certain cultures and knowledge that largely formed the basis for rationality. At the same time, colonialism discouraged a total integrity of other forms of knowledge, particularly IK. However, the latter part of the 20th Century saw a growing interest in IK. In a promotional flier for the Centre for Indigenous Knowledge for Agriculture and Rural Development (CIKARD), the late Michael Warren (1992) argued that IK has value not only for the culture in which it evolves, but also for scientists and planners outside that culture. Development professionals are increasingly seeing the value of this form of knowledge in solving agricultural and environmental problems. Several research institutes and resource centres aimed at monitoring; promoting management and utilising IK have mushroomed around the world in the last 20 years. Although many of these centres are mainly located in developed countries, they have facilitated the establishment of similar centres and networks in Africa. Similarly, various means of or delivery systems for sharing ideas on IK have been established. For instance, the Indigenous Knowledge and Development Monitor was established in 1993 to cater for "people interested in IK". A World Wide Web version of the publication is available on the Internet. The growing recognition of IK in making decisions, solving problems and dealing with societal development issues on a wider scale is best summarised by this Editorial (1993: 1):

Knowledge produced by universities and research institutes around the world is gathered, documented and disseminated in a coherent way ... the same should be done with community-based, local or indigenous knowledge ... It should be included, alongside the more usual scientific knowledge, as part of national and international discussions and development and the strengthening of intellectual capacity.

Knowledge management (KM), as will be elaborated on later, involves the processing and handling of intellectual capital within and between organisations and communities. It facilitates knowledge generation, sharing and reuse. While technology is crucial to $\mathrm{KM}$, the human dimension plays an important role in knowledge creation and knowledge renewal. Knowledge generation, sharing and reuse are key requirements for organisational and community effic-iency and productivity. However, by its very nature IK has traditionally not been viewed in the business sense as "capital". It has tended to be "exclusive" at times, susceptible to suspicion; and at others, to abuse.

This paper explores the extent to which KM methodologies and principles can be used to manage IK for the benefit of all. In doing so, the paper will identify the challenges of using the standard KM principles and processes for IK management. It suggests possible solutions, and highlights some examples used for overcoming problems and applying KM techniques for the management of IK and the development of KM systems for IK. The paper presents a discussion on KM and IK, their philosophies and principles. It then deals with an assessment of the usability of KM principles for managing IK. The paper concludes with our thoughts about internationalising IK, while at the same time making sure that the legitimate "owners" of the intellectual property in IK are protected for the benefit of all.

\section{Knowledge and society}

Any society or community has a peculiar way of evolving. Traditional beliefs and practices are not only important to the people who own and understand them, but also to those who subscribe to a common societal value system. Societies today face much more complex human problems than in the past. Complex problems require complex solutions. In order to deal with complex problems, facilitate development and manage change, "modern" communities and/or individuals must borrow and adapt ideas and practices from other sources, including traditional (indigenous) and scientific communities. We can illustrate this by using the example of the democratic process in South Africa in the early 1990s. The democratic process, which was a very complex "problem", required mastering 
different ideas to accommodate different people with different backgrounds and value systems. It was not surprising therefore, to note that some aspects of the format of the Convention for a Democratic South Africa (CODESA) talks that were a major part of this process were said to have been based on the "best" traditional practices of lekgotla, that is a place or locale where men assemble, often at the chief's kraal, to discuss or debate issues of concern to the community. While there are "good" ideas that can be adapted from different communities for the betterment and enhancement of humanity, there are also "bad" cultural beliefs and practices that are counter-productive and need refinement. The process of refining traditional and local values is a complex one. We are mindful of the tension between the complete erosion of traditional values and beliefs and giving preference to imported ideas. A discussion of such a tension requires a different paper.

In order for an individual to cope with daily problems and, at a higher level of complexity, make a significant difference or change in his or her life, society or community, knowledge is necessary. Probst et al. (1999: 24) define knowledge as "the whole body of cognitions and skills which individuals use to solve problems. It includes theories and practical, every-day rules and instructions for action". Davenport \& Prusak (1998: 5) define knowledge as follows:

[A] fluid mix of framed experience, values, contextual information and expert insight that provide the framework for evaluating and incorporating new experiences and information. It originates and is applied in the mind of the knower. In an organization [or community] it often becomes embedded not only in documents or repositories but [also in] organizational [and community] routines, practices and norms.

Simply stated, knowledge is know-how. It is one's understanding of why and how things work or should work, combined with the step-by-step skills for accomplishing a task. Knowledge is what one is familiar with owing to experience and is thus internalised as part of one's life. It must be noted, however, that an individual, organisation or community cannot possess or internalise all the knowledge that is required to deal with all the "problematic" situations that are, or may be, encountered. At the same time, the level and amount of knowledge that an individual, organisation or community possesses at a particular time cannot resolve and facilitate all the problem-solving and decision-making processes encountered in the course of the "knower's" existence. The implications of this are that an individual or organisation must learn continuously and acquire and generate new knowledge. They must be aware of who owns knowledge that is relevant and appropriate to particular situations.

Knowledge is directly related to information and data, but they are not synonymous terms. Information can be defined as ideas, facts, imaginative workings of the mind and valuable data that are potentially useful in decision making, question answering and problem solving (Kaniki, 1989: 19). It reduces uncertainty and can lead to the state of knowing. To be useful, information must be applied and contextualised. Therefore, information in itself is not knowledge and does not solve problems, but simply makes one aware of and provides possible courses of action. Data, on the other hand, are symbols with rules of syntax applied to them. Data and information can be context independent, in that they can exist independent of a person or community. However, knowledge is bound to a person, organisation or community. It is constructed by individuals and represented by their beliefs.

Knowledge may be categorised into two types or classes with common characteristics. It is critical, particularly in a discussion of KM, to have a clear understanding of these types. Nonaka (1991) identifies the two types of knowledge as "explicit" knowledge and "tacit" knowledge:

- Explicit knowledge is formal and systematic in nature; it is expressed in symbols and words. For this reason, it can be communicated easily and shared in product specifications, scientific formulae or computer programs. It can also be recorded or stored in artefacts, in printed, audiovisual and electronic format.

- Tacit knowledge, on the other hand, is highly personal. It is informal, represents personal knowledge and involves personal beliefs, values, intuition and insight. It is hard to formalise and therefore difficult to communicate.

Knowledge exists in a variety of forms. In other words, there are different outward aspects or modes in which knowledge, whether explicit or tacit, manifests itself. The most common forms are scientific knowledge and indigenous knowledge. The form that is of particular interest in this paper is, of course, that of IK.

\section{Indigenous knowledge: types, systems and use}

What is IK? Indigenous knowledge has been defined as a cumulative body of knowledge generated and evolved over time, representing generations of creative thought and actions within individual societies in an ecosystem of continuous residence, in an effort to cope with an ever-changing agro-ecological and socio-economic environment. 
Terms like "traditional", "local", "community" and "rural people's knowledge" are used interchangeably with IK (Thakadu, 1998: 3). It is the sum total of knowledge and skills possessed by people belonging to a particular geographic area, which enables them to benefit from their natural environment. Such knowledge and skills are shared over generations, and each new generation adds and adapts in response to changing circumstances and environmental conditions. This suggests that IK is fluid and does not necessarily operate within the confines of formal organisations, although, of course, it exists within specific environmental boundaries.

Indigenous knowledge is unique to a given culture or society; it is dynamic and based on innovation and practical experimentation. It is not easily codifiable for fear of loss of some essential properties. It is also referred to as local knowledge or traditional knowledge. It is contrasted to and differentiated from Western, scientific or modern knowledge, which may be developed by research institutions and universities. The main feature of IK is that it is mainly transferred by word of mouth. It is therefore largely undocumented, making "bibliographic" control in the traditional sense almost impossible. It must be noted, however, that IK and its systems are not confined to developing countries although, in this paper, our emphases are on IK from and within the developing countries. There are also several subforms or sources on which IK draws. Thakadu (1998: 90), for example, concludes that IK systems and practices among the Sankuyo and Xai Xai communities of Botswana were expressed in taboos, totems, customary laws, beliefs, environmental ethics and values, and that they were passed from generation to generation orally. Examples of some of these subforms of IK from various traditional communities are presented below.

\subsection{Beliefs}

Indigenous knowledge can be reflected in the form of the beliefs of a community based on its religion and/or culture, for example ancestral worship and the belief that the ancestors are the community's intermediaries with God, if not gods in their own right. Many communities believe that ancestors can communicate with individuals. Hence, as part of a wedding ceremony, for example, an animal is slaughtered in the yard, rather than at an abattoir. Through this process ancestors are requested to pave the way for a healthy marriage and partnership. Animals such as goats, sheep or cows (go phasa badimo) are also slaughtered in many African communities as a form of "cleansing" if an individual's or community's life is not unfolding according to expectations and wishes.

\subsection{Indigenous knowledge in medicine}

Herbs collected in the wild are key sources of traditional African medicine. Both general and specific plants are used for various health conditions. For example, the yellow star, which is commonly known as the African potato (leraka), is considered a useful tuber for building the immune system and controlling high blood pressure. Bitter aloe (sekgokgopha) is used for cleansing the body from toxins and free radicals. Herbs are used as a key or primary medicinal treatment and are accessible to rural communities and the urban poor. Increasingly, traditional healers are practising in the national health systems. In a paper presented at the Indigenous Knowledge Systems conference held at the University of Venda in 2001, Afolayan discussed phytomedical research in the Eastern Cape. He pointed out that traditional healers are recognised by some medical aid schemes that cover phytomedicine.

Herbs are not only used as traditional medicine for treating ailments, but also as preventative medicine. For example, in many African communities the bark of specific trees is harvested and chewed for cleaning teeth and for protection against dental problems. For centuries, the San clan of the Kalahari Desert has chewed the Hoodia cactus to stave off hunger when on a hunting trip, which often takes several days.

\subsection{Human resources and indigenous knowledge}

In many African communities, kinship determines who should play a decisive role in community development and leadership. Traditionally, communities worked together as a team, guided by the chief or village headman. The head of the community marshalled or could marshal resources within the community to assist those who were not able to look after themselves. This may partially explain the rarity or complete lack of destitute and homeless people in some traditional societies. If a person was found to be in dire straits, but not simply because of laziness or lack of effort, the chief or village headman would call letsema (communal labour). Strong, healthy men and women in the village would be identified to build houses for those who could not do this on their own. The chief or head of the community not only controls the physical resources, but is also the custodian of the valuable knowledge resources available within the community. He or she is therefore able to call upon those persons who may have special powers, such as rainmaking or medicinal know-how, to deal with a particular situation as necessary. Traditional leaders had 
the authority to make final decisions. Nowadays, the situation is different, with democratic governance, where consultation with stakeholders is becoming the norm.

\subsection{Transfer of indigenous knowledge technology}

Human beings can do a great deal with resources in their environment, particularly in traditional societies. For instance, in some traditional communities women use cow dung to decorate the walls and floors of their houses. It is also used to seal the lids of baking pots to keep an even temperature in the pot when baking bread. Similarly, the production of charcoal involves sophisticated technology. Since time immemorial, rural charcoal producers have used fresh logs of specific trees, instead of dry wood. They collect the fresh logs and cover them with earth, leaving small spaces to allow oxygen into the "furnace" to burn the wood slowly. The process takes days to complete, but it allows combustion to occur slowly and produce charcoal, rather than reduce the logs to ashes.

\subsection{Indigenous knowledge in the education process}

The traditional methods of education were (and continue to be) practised through initiation schools. Here young community members learn about tradition itself. They learn about various beliefs and about having respect for oneself and others, particularly for elders. Through observing the behavioural and seasonal migration of prey and the tell-tale signs of weather changes, for example, the youths learn about the connectivity of the environment and humanity. A body of knowledge is continually being accumulated and preserved to be shared with successive generations. For instance, young girls are instructed not to enter the kraal, lesaka, otherwise they will become infertile. Although the scientific reality of this belief may be difficult to prove, it serves another purpose, namely that of security. One of the main reasons for "closing off" women from the kraal is because it is often heavily strengthened to protect the animals, mainly against theft.

\subsection{Communication of indigenous knowledge}

Cultural festivals were, and continue to be, organised to entertain, inform and educate through dance, song and drama. In individual families, the elders would tell stories after supper and recite proverbs based on the customs of a particular ethnic group. The "language" used in IK communication is unique, and quite different from the everyday language of the given community.

\subsection{Indigenous knowledge in farming practices}

One of the main areas in which IK is very rich is that of farming practices and agriculture. Examples of local soil classifications and herbal medicines have been tried, tested and seen to work even in the scientific arena. Indigenous people practise intercropping, that is, they plant different crops in the same field. For instance, mealies (maize or corn), mabela and beans are intercropped to retain soil nutrients. When the land lies idle for a season or so, the soil is covered with ash to protect it from unwanted insects.

\subsection{Food technology and fermentation techniques}

Various food preservation and storage systems have been developed and effectively applied in traditional societies. For example, mopani worms (ifishimu) are a great source of protein. They are eaten not only in South Africa, but also in many parts of eastern, central and southern Africa. They usually appear at particular times of the year and are therefore harvested during specific seasons. However, they can be preserved for many months or years simply by boiling them in water, sometimes salted and sundried. A similar method is used for preserving African spinach (morogo). The use of IK in the brewing of beer is also well developed among traditional communities. Generally, IK in food processing and preservation is highly developed in many communities.

\subsection{Arts and craft}

Decorative and utility products are made from wood, clay, beads, fabrics, soil and other materials. The technologies and techniques used in each community are often unique and highly sophisticated. For instance, particular soil types are found and sold in specific areas. The right combinations of soil and clay are mixed with cow dung and used to decorate walls and floors in traditional mud homes, especially among the Ndebeles in the north of South Africa and in Zimbabwe. This provides an artistic and colourful effect. Special types of clay are used for making specific types of pots. Decorations on the pots may convey particular messages and/or indicate the specific use of the pot. For example, the Zulus have special types of pots that are made and decorated for cooking, or storing beer.

One major peculiarity about IK is that it is mainly tacit knowledge. IK is generally:

- not recorded or written down 
- regarded as informal and unscientific

- not easily codifiable

- readily available

- transferred by word of mouth.

Added to the above characteristics is the fact that the level of IK is often associated with age. The elderly have different subforms and levels of knowledge compared with the young. As indicated above, traditional authority and kinship also determine the amount of IK a person has access to and/or controls. Communities and their members hold different types of knowledge, which may not be accessible to all. However, in order for the knowledge contained in a community to be effective and applied to the benefit of all, it must be shared. In traditional communities, knowledge sharing is facilitated and guided by the head of the community.

Many forms of IK exist and have been generated, passed on, shared and practised effectively for different purposes. As indicated above, IK is as important as other knowledge and can provide unique solutions for dealing with local and even non-local situations. It is disheartening to note that some of this knowledge is disappearing or has already disappeared without notice. Owing to its oral tradition, as well as the introduction of new technologies, the preservation and utilisation of IK are at risk. For instance, it is not uncommon to see some piece of IK being introduced as a modern idea, and then transferred across the borders without recognition of and compensation for the originators of the intellectual ideas. This is where knowledge management becomes more relevant.

\section{The rise of knowledge management}

While the 1960s saw the rise of the "science of knowledge utilisation", the 1990s saw the advent of the knowledge management era. Barclay \& Murray (1997) present a brief, but informative, history of KM. They observe that a number of management theorists like Peter Drucker, Paul Strassmann and Peter Senge contributed to the early evolution of KM. Both Drucker and Strassmann raised the profile and importance of information and explicit knowledge as resources in organisations. Senge, on the other hand, is credited with popularising the concept of the learning organisation and the cultural dimension of managing knowledge. These areas have become key components of KM. Of course, some early works of the 1960s and 1970s, like those of Everrett Roger on communication and the adoption process of technology, particularly in agriculture; and those of Thomas Allen and colleagues at the Massachusetts Institute of Technology dealing with information-seeking behaviour and use, which were also highlighted by Havelock et al. (1969), have contributed to the evolution of KM.

However, it was not until the 1980s, as Barclay \& Murray (1997) further argue, that there was a marked difference in the development of KM per se. The development of systems for managing knowledge that relied on the work in artificial intelligence and expert systems gave rise to the concepts "knowledge acquisition", "knowledge engineering", "knowledge-based system" and "computer-based ontologies". In the field of library and information science (LIS) too, the rise in the amount of research and developments in user studies was marked in the 1980s. However, in LIS the main focus of user studies was on information rather than on knowledge and as defined above, information simply brings awareness. To be useful, it must be internalised and applied. One of the main criticisms of information user studies therefore, has been the limited progress made in the area of cognitive processes, the conversion of information to knowledge, its application and the measurement of the impact of information per se. Suffice it to say, however, that some proponents of user studies (including ourselves) have always believed that the logical extension of information seeking and use is knowledge generation, application and utilisation, and thus KM.

Allee (1997: 12) reports that in the 1990s "writers like Ikujiro Nonaka and Hirotaki Takeuchi described the dynamics of project team formation ... [and there has been] a growing body of stories [of] countries that are implementing knowledge practices". In their brief historical review, Barclay \& Murray (1997) also recognise the work of Nonaka and Takeuchi and note that the easy availability and widespread use of the Internet in the 1990s enhanced the development of KM. The 1990s also saw a rise in the number of conferences and seminars on KM and of organisations focusing on knowledge to gain themselves leverage and competitive advantage. Allee (1997: 8) further observes that today "we are stretched to the limits in our ability to integrate, synthesise, incorporate and adapt", and quotes Valery Kanavsky who states that "the fundamental building material of the modern corporation [and community] is knowledge". She concludes that knowledge creation and knowledge utilisation have become an even bigger concern. 


\section{Defining knowledge management}

What then is knowledge management? Corrall (2001) notes that the most widely quoted definition of KM is the one provided by the Gartner Group, which states that:

[KM is] a discipline that promotes an integrated approach to identifying, managing and sharing all of an enterprise's information assets. These information assets may include databases, documents, policies and procedures, as well as previously unarticulated expertise and experience resident in individual workers.

Snowden (1999: 8-9) has defined knowledge management as the "identification, optimisation and active management of intellectual assets, either in the form of explicit knowledge held in artefacts or as tacit knowledge possessed by individuals or communities". He also states that the optimisation of explicit knowledge is achieved by consolidation and by making the artefacts available. This process is one of the traditional and major activities of library and information services. Optimisation of tacit knowledge, on the other hand, is achieved through the creation of communities to hold and share the tacit knowledge, and to allow it growth. The definition given in the Knowledge management glossary (1998) is that KM is a body of methods, tools, techniques and values through which organisations can acquire, develop, measure, distribute and provide a return on their intellectual assets. Intellectual assets or intellectual capital is the knowledge that is valuable to an organisation, and includes human capital, structural capital and customer capital. Botha \& Van Rooyen (2000: 30) define knowledge management simply as the collection of processes that govern the creation, dissemination and utilisation of knowledge (insight and experiences) to fulfil organisational objectives.

These definitions emphasise processes of finding, capturing, sharing and exploiting the available knowledge and information for the success of one's organisation over its competitors. The key components of organisational knowledge are people, processes, products, customer interactions and information systems. Knowledge management involves imparting and/or facilitating acquisition of the right knowledge and information to the right person within an organisation, at the right time and in a manner most appropriate to him or her. It involves identifying and applying efficient methods of business practices and empowering benefits to all role-players in and members of an organisation.

Put differently, KM involves the processing and handling of intellectual capital within and between organisations and communities. It facilitates knowledge generation, sharing and reuse. Information and communication technologies are critical in facilitating many of the KM processes. However, while technology is crucial to KM, the human dimension plays an important role in knowledge creation and renewal. Knowledge generation, sharing and reuse are requirements for organisational and community efficiency and productivity. The whole purpose of KM is to facilitate knowledge generation, sharing and reuse for the common good or benefit.

\section{Principles and processes of knowledge management}

How is KM applied? What is the basis for and what are the guiding principles and/or processes of KM? Barclay \& Murray (1997) observe that an overarching theory of KM has yet to emerge. This is mainly because the practices associated with managing knowledge have their roots in a variety of disciplines. Corrall (2001) notes in this respect that various professional groups, notably those from the human resources, information technology (IT), and library and information sciences are staking their claims, seeing KM as an opportunity to move to centre stage. Barclay \& Murray (1997) note that being a cross-discipline, KM draws on a wide range of disciplines and technologies. These include: cognitive science; expert systems, artificial intelligence and knowledge-based management systems; computer-supported work (groupware); LIS; technical writing; and document management. Other disciplines on which KM draws include decision support systems; semantic networks; relational and objective databases; simulation; and organisation science. It appears that drawing on a variety of disciplines is what should be considered, seeing that KM is interdisciplinary. Despite the lack of an overarching theory for KM, several principles of and approaches to KM have emerged. In discussing these principles, we have drawn heavily on the works of Davenport (1998), Barclay \& Murray (1997), and Probst et al. (1999).

Barclay \& Murray (1997: 7-9) identify three approaches to organisational KM: the mechanistic, cultural or behavioural, and systematic. Probst et al. (1999: 30) identify the following as the core processes of KM, which also guide its principles: knowledge identification; knowledge acquisition; knowledge development; knowledge sharing and distribution; knowledge utilisation and knowledge retention. 
Other champions of KM have referred to three kinds of approaches to effect knowledge management, namely, the mechanistic, cultural/behavioural and systematic approaches:

- The mechanistic approach to KM focuses on the application of technology and associated resources as tools for facilitating access to information, and helps organisations achieve more with less.

- The cultural/behavioural approach, on the other hand, emphasises innovation and creativity, which are important for learning organisations. The introduction of new ways of doing things, of new experiences that force organisations and communities to adopt a holistic view of their relationships with the environment, further influences community and organisational culture.

- The systematic approach uses systems thinking, which incorporates all aspects of KM to ensure continuous evaluation and a sustainable process. This requires the recognition and utilisation of the various cross-disciplines to develop KM systems and processes.

As argued earlier, no one individual, organisation or community can possess or internalise all the knowledge required to deal with all the "problematic" situations that may be encountered. Likewise, the level and amount of knowledge that an individual, organisation or community possesses at a particular time cannot resolve or facilitate all the problem-solving and decision-making processes encountered in the course of the "knower's" existence. The implications are that an individual or organisation must be continuously learning, acquiring new knowledge and generating new knowledge, and be aware of who owns appropriate knowledge that is relevant to particular situations. Based on this assumption, the emphasis in today's environment is on learning how to learn and/or changing organisations into learning organisations.

Probst et al. (1999: 164) argue that it is vital that knowledge be shared and distributed within an organisation (and community) so that the whole community can use isolated information or experience. The Chief Executive Officer of Anderson Consulting Global (2000: 8), for example, states that knowledge sharing is "the essence of how we bring innovations to change the way the world works and lives". If learning organisations understand this, knowledge will be volunteered without doubt. The question, however, is who needs to know, who is able to know, how much of what knowledge should be shared, and how can knowledge sharing be facilitated? Individuals in an organisation must learn how to learn. In other words, they must learn how to find sources of knowledge, utilise it and share it. However, trust is a keyword in KM, particularly with respect to knowledge sharing. As Snowden (1999: 42) argues, without trust among the members of the community or organisation, it will be impossible to tap the tacit components of the community or organisation's intellectual assets. This is especially real in rural communities, where the elders and heads of communities are carriers and custodians of knowledge and can only share it with those whom they trust. The key issue of course, is to identify the factors that motivate people within an organisation or community to share their intellectual assets. A learning community and organisation build collaborative relationships in order to draw strength from the diverse knowledge, experience, capabilities and ways of doing things that people and communities in general have and use.

Davenport (1998) identifies ten principles that govern or can guide KM processes in organisations. These also reflect some of the issues other scholars have raised about KM. The principles, incorporating ideas from other authors, are presented below.

1. Knowledge is an asset that must be identified, captured, and have value added to it. To do this requires an investment of resources. Knowledge management is an expensive process, which involves knowledge capture and adding value through editing, repackaging and so on. It also involves developing knowledge categorisation through processes such as classification, and developing and applying IT infrastructure for storage and distribution. Know-ledge management involves educating people about the techniques of creating, sharing and using knowledge within and outside their community or organisation. Probst et al. (1999: 70) observe that in many cases, valuable knowledge assets may go unnoticed and unused, and managers may not know that a company or organisation has internal experts on a given subject. An organisation can waste time, and indeed money, reinventing the wheel, because it does not know that the solution already exists. In this respect, therefore, Davenport (1998) argues that KM is expensive, but so is stupidity.

2. As noted above, KM is interdisciplinary and aims at dealing with cross-disciplinary problems. Therefore, the effective management of knowledge requires a hybrid of solutions involving people and technology. Today's problems are often complex. The impact of globalisation, for example, is such that problems that befall countries and people as far away as the United States of America or Singapore may have immediate and profound effects on South Africa and its rural communities. Similarly, the positive influences that developments in ICTs may have 
in an organisation need to be reflected and benefit most, if not all, communities. Today's problems are often complex, requiring complex solutions with ideas adapted from several sources, disciplines and communities. No one individual or organisation possesses all the required knowledge and skills. Therefore, given the mixture of skills needed to deal with complex day-to-day problems, and particularly those affecting competitive advantage, we need to construct hybrid KM environments using both human and technological resources in a complementary way.

3. We are all familiar with the saying "knowledge is power". This has become more of a reality today than in the past. Knowledge is associated with power, money and success. Whoever has the know-how for doing something better is bound to "sell" that knowledge for profit, recognition or simply respect. Therefore, managing knowledge is highly political because it involves determining who has access to and can utilise and derive benefits from the valuable knowledge resources.

4. Like every resource in an organisation, knowledge must be managed. In other words, KM requires knowledge managers. Key resources in organisations require managers to facilitate their generation, distribution and use. If not appropriately managed, resources can be misused and thus depleted. Collecting and categorising knowledge, establishing knowledge-oriented technology infrastructure and monitoring the use of such knowledge are some of the tasks that KM managers should perform. Related to this is of course, the facilitation of the creation, distribution and use of knowledge by members of an organisation or community.

5. A key element of KM is knowledge sharing within a given environment or community. However, in order to share knowledge effectively for the benefit of the organisation, and its members, and to facilitate productivity, knowledge maps must be generated. Maps of knowledge assets show where and how particular knowledge assets are stored in the organisation. Organisations benefit more by knowledge mapping and by marketing the available knowledge in a transparent manner, than by operating in a hierarchical fashion.

6. Although KM emphasises sharing knowledge, sharing and using knowledge are often unnatural acts. People often keep knowledge to themselves in order to preserve their power and prestige. However, Probst et al. (1999: 163) argue that although "divide and conquer" may work in politics, it would be dangerous to play politics with knowledge, because information and experience can only be used to the benefit of the whole organisation if they are available to those who have to make decisions. Organisations have to identify and use effective motivators and motivating techniques to facilitate knowledge sharing. At the same time, "knowers" and generators of knowledge must be assured that they will be appropriately compensated, rewarded and/or recognised for their knowledge. Organisations should also invest in developing knowledge sharing and distribution techniques and best practices. The application of ICTs in knowledge networks is crucial in modern society.

7. Another important KM principle identified by Davenport (1998) is that KM means improving knowledge work processes. The organisation must facilitate knowledge generation, utilisation and transfer by putting in place appropriate policies, resources and facilities. However, improving knowledge work processes may not necessarily be as simple and straightforward as it sounds. It is complex and requires financial, human and material resources. As stated above, it may well be an expensive process.

8. Information and knowledge in themselves are not useful unless they are applied to specific situations. Access to knowledge, while important, is not sufficient. As Davenport (1998) argues, access to knowledge is only the beginning. To be useful and profitable, knowledge must be applied. Explicit knowledge, for example that which is contained in patents, is always available and accessible, but in order to become useful it must be applied. This issue is even more complex with respect to tacit knowledge. A member of an organisation or community may have access to another person who has the know-how for a particular task. However, if the person with the knowhow does not share or use his or her knowledge to accomplish a task, then the knowledge is "irrelevant".

9. Similar to the process of scientific research, where research builds on other works, KM never ends. Knowledge generation, its utilisation and transfer are necessary because new problems and situations arise and require new solutions. The whole purpose of scientific research is discovering new and adding to old knowledge in order to deal with new phenomena. One of the cornerstones of LIS is the recognised fact that the information needs of people change with time, circumstance and environment. Therefore, information provided even for similar needs must suit the situation and circumstance. Likewise, the need for new knowledge and its application changes with time. Therefore, there is no stage when knowledge is fully managed.

10. Another key principle of KM is that it requires a knowledge contract. Human beings are naturally competitive creatures and strive to improve their living conditions. Maynard (1978: 1) argues, however, that in spite of their 
natural competitive tendencies, humans "have learnt that the forces of competition must be balanced with an equal measure of cooperation if all [humans] ... are not to be destroyed by the process". He goes on to say that "successful societies have been those that have achieved the most effective balance of competition and cooperation". Humans have recognised that money, time, effort and other resources invested in the creation and/ or development of intellectual property or know-how (knowledge) must be recognised and rewarded. Kaniki (2001: 3-4) points out that communities, national governments and international organisations are responsible for protecting individuals' rights and property. Legal frameworks, rules and regulations, such as copyright laws, patent laws, trade marks and trade laws, have been put in place. They not only encourage competition and cooperation, but also protect individuals' and government property. In addition to legal frameworks and laws, human beings depend on conventional practice, moral values, judgement and obligations or ethics in their interaction with one another and in the protection of their rights and those of the community. Therefore, it is important to identify who owns what and has the right to use an individual's knowledge.

\section{Application of knowledge management principles to indigenous knowledge}

The description and definitions of KM processes, and the systems created to facilitate these processes, emphasise and/or seem to imply that there are, or should be specific boundaries within which knowledge can be effectively utilised. In many instances, these environmental boundaries are in the form of formal organisations or business enterprises. A further implication of the above definitions of $\mathrm{KM}$ is that information and knowledge can readily be interpreted as "capital" or valued or interpreted as profits. The definitions further emphasise sharing knowledge, often through the use of ICTs. By its very nature, IK, which is the main focus of this paper, has traditionally not been viewed in the business sense as "capital". It has tended to be "exclusive" at times, and susceptible to suspicion and abuse.

Although many definitions of KM emphasise formal organisations, businesses and profits, they do not exclude the management of other forms of knowledge, including IK, within fluid and open (traditional) communities within which IK is often applied. Merali (1999: 80-81) uses a metaphor of an ecological community to define a KM community: "In KM, a community of practice is defined as an interdependent group of people inhabiting the same information space, interacting with each other through resources and other relationships." He identifies three elements that are necessary to develop such communities. These are a clear identity of the community and what it stands for; a sense of belonging and reciprocal attachment among members of the community; and the concept of self and non-self, that is a shared sense of who and what the parts of the community lie within it and what lies outside. This definition of the KM community of practice and the elements seems to cover the ethos and philosophies of traditional societies or communities and the IK within these communities. However, it is necessary to examine the extent to which the principles of $\mathrm{KM}$, as advanced by Davenport and other scholars, are applicable to IK.

One of the key principles raised by Davenport (1998) is that KM is expensive. Financial, material, human and other resources are necessary in order to manage knowledge. Unlike scientific knowledge, IK has often been marginalised, at times treated with suspicion or simply ignored. An important step in recognising the usefulness of anything in society and thus warranting the allocation of limited resources to it is, firstly, raising awareness about the issue. In the introduction to this paper we referred to the growing interest in the role that IK can play in society on a wider scale.

In the late 1980s and early 1990s, more centres for IK were established around the world and networks among them were intensified. For example, based on meetings in the Hague and Leiden in May 1992, the Centre for International Research and Advisory Networks (CIRAN), the Centre for Indigenous Knowledge for Agriculture and Rural Development (CIKARD) and Leiden Ethnosystems and Development (LEAD) agreed to collaborate on a variety of networking activities "based on the growing global network of IK resource centres". Some of the activities agreed upon, and to be based at CIRAN, were the publication of a quarterly Indigenous Knowledge and Development Monitor. This newsletter, which has blossomed into a journal providing detailed articles and informative news items on IK, began publication in February 1993 and continued as Indigenous Knowledge World Wide since January 2002. It aims at promoting the dissemination of local knowledge as a service to the international development community and all scientists who share a professional interest in IK. It is circulated around the world and has been issued free of charge to "subscribers" from developing countries. There is also a Web version of the 
journal, which is available at http://www.nuffic.nl/ciran/ikdm/. The work of international IK centres, including publications such as the aforesaid one, have promoted IK and made those who initially may have been sceptical about IK appreciate its role in dealing with human development issues. Initiatives such as the Interim Committee on Indigenous Knowledge Systems in Southern Africa, which came together in 1995 to promote the mapping, conservation and application of IK within the southern African region, can be traced to the collective work of these international centres.

Another activity agreed upon at the May 1992 meeting between CIRAN, CIKARD and LEAD was the establishment of an electronic mail capacity to link the centres, and of a global database reflecting IK and technologies appropriate to development. With the rapid developments in ICT at the close of the 20th century, and the increase in the availability and usage of Internet facilities, particularly the World Wide Web, aspects of knowledge management for IK have grown in leaps and bounds. Awareness of and information about IK have continued to rise. Several websites are related to IK and are either visited by interested parties or accessed simply by chance. Most importantly, the development of best practices for IK has been under way and facilitated by organisations such as the United Nations Educational, Scientific and Cultural Organisation (UNESCO) and other independent centres, like Nuffic-CIRAN, who have provided the necessary financial, human and material resources. In an e-mail calling for contributions of best practices on IK, Spiegeler (2001) reports that in 1998, UNESCO's Management of Social Transformations Programme (MOST) and Nuffic-CIRAN put out a call for best practices related to IK. In defining the focus of the project, she states the following:

A best practice is an approach or methodology that has proven effective for a particular purpose in a particular context, but could also be effective in another context if properly adapted and applied. A best practice is thus held up as a model worth emulating in other parts of the world. Good examples of such practices will help persuade development professionals and scientists that indigenous knowledge is an invaluable resource that must be taken seriously. This is the reason for documenting as many such practices as possible and making them accessible to a wide audience.

Today, the descriptions of practices are available through several sources. They can be accessed online through a portal to the database maintained by UNESCO-MOST, at: http://www.unesco.org/most/bpikreg.htm. Apart from simply providing awareness about the role of IK, these international initiatives have invested the necessary resources and expertise for facilitating knowledge capture, documentation, adding value, developing IK, knowledge categorisation, and developing IT infrastructure and applications for the distribution of IK. In addition, these activities and the work of the various organisations facilitate the sharing of IK. They also apply a hybrid of solutions involving people and technology to managing knowledge.

One of the main questions that may be asked with respect to international and even national KM initiatives for IK, such as the ones described above, is the protection of intellectual property rights. In dealing with intellectual property, one of the key issues is the identification of the originator or owner of the know-how. A community that develops and applies particular IK as their culture generally owns the IK. Hence, communities know which practices are more common in some regions or areas, and which are less common or not found at all in others. In the process of instituting intellectual property rights and/or mapping IK, it is possible for each community to identify and specify the IK that belongs to it. The individual creativity and invention will have to be recognised and protected. This aspect is addressed by the document Guidelines for a proposal of a best practice related to the use of indigenous knowledge in development, which is used for the UNESCO-MOST and Nuffic-CIRAN best practices project referred to above. A section in the document deals with indicating the origin of a given IK practice or knowhow in terms of a community and country. The difficulty in linking IK to particular communities may be related to tacit IK, like that of the sangomas and inyangas, which is imbedded in themselves. It is often not easy, and in fact generally impossible, to ascribe particular practices related to the work of these persons to particular communities.

A number of international conventions and agreements, like the Berne Convention on Copyright and the Agreement on Trade-Related Aspects of Intellectual Property Rights (TRIPS), as well as international patent laws, attempt to protect intellectual property from piracy and abuse internationally. There are also national intellectual property laws and regulations. However, as Quiroz (1994: 13) indicates, "the existing intellectual property rights agreements do not give full and proper recognition to the rights of indigenous and local communities to their own knowledge, innovations and practices".

Where such property rights and agreements cover indigenous communities and their IK, enforcement of the law or sanctions require policing and advocacy. Often such advocacy comes in the form of an independent body, 
organisation or community itself acting as the custodian of the IK and, at the same time, as the watchdog for any transgressions. It means that a body or persons must take the responsibility of making sure that a community's IK is not abused. To illustrate, the article "The San tribe to get medicine royalties" (Anon., 2001) reports:

The Khomani tribe may soon receive a portion of sales from an anti-obesity drug derived from a Kalahari cactus. The San clan has chewed the Hoodia cactus to stave off hunger on hunting trips for millennia. The Council for Scientific and Industrial Research (CSIR) isolated the active ingredient and signed over commercial rights to Phytopharm of the UK in 1997, which licensed a patented medicine to Pfizer in 1998 for US\$32 million. The San claimed that the drug industry profited at their expense and filed suit. The settlement should be signed at the end of November 2001.

In spite of the fact that details of this decision or judgement were not included in the short newspaper article, it would not be far from the truth to speculate that the process must have taken a long time to resolve. It must also have involved local and international lawyers who will also benefit from this pay-out!

At the national level in South Africa, there is evidence of activities of knowledge management of IK. One of the critical issues of KM is the institutionalisation of the process. Within organisations there must be a unit (knowledge managers) responsible for knowledge; in a fluid environment or at macrolevel there must be "ownership" of the process and/or custodians of KM. In South Africa, the National Department of Arts, Culture, Science and Technology has expressed its interest in and concern for IK nationally by establishing a directorate of IK within the Department. National recognition of IK in South Africa is also reflected in the work of the National Research Foundation (NRF). The objective of the NRF (n.d.) is as follows:

To support and promote research through funding, human resource development and the provision of necessary research facilities, in order to facilitate the creation of knowledge, innovation and development in all fields of science and technology. In so doing it contributes to the improvement of the quality of life of all people of South Africa [and indeed internationally].

The government is the main funder of the NRF. The Research Support Agency (RSA) of the NRF has a number of directorates that plan for and guide a variety of programmes and activities in line with South Africa's priorities and needs. The priorities are reflected in focus areas. One of the RSA's focus areas is indigenous knowledge systems (IKSs) It is the NRF's view that IK and its role in the community must be understood from an integrated perspective, which includes both spiritual and material aspects of a society, as well as the complex relations between them. The NRF further believes that it is necessary to understand and explore the contribution of IK to local development. Echoing Warren (1992), the NRF (n.d.) states that:

IK systems should be brought into the mainstream of knowledge in order to establish their place within the larger body of knowledge. The socio-economic potential of IK should be considered, as well as the non-socio-economic values such as the impact of IK on lifestyles and the ways in which societies are run. Research into [an] IKS, however, should be carried out with the participation of the communities in which it originates and is held. The aim of the IKS focus area at the NRF is to develop theoretical and methodological paradigms within which to understand the specific characteristics of IKSs; to shed light on the role of IK in nation building; and to develop research capacity in the field of IKS.

To achieve these aims, the NRF focuses its research project funding on dealing with the production, transmission and utilisation of IK and technology; the role of IK in nation building; and IK at the interface with other systems of knowledge.

Not only does the NRF support IK research and in effect contribute to KM through the IKS focus area, but also the major directorate of one of its research support agencies is specifically concerned with Knowledge Management and Strategy (KMS). Among the many activities of this Directorate is the management of research information and the provision of KM strategies for the NRF and institutions that network with it. Among the research information activities of the Knowledge Management and Strategy (KMS) Directorate are the development, management and maintenance of the NEXUS database. It also has records of South African experts, and of research conducted by some of these persons and that funded by the NRF. This includes research on IK as a matter of course. Another research information activity of the KMS Directorate is the South African Data Archives (SADA), whose main mission is to acquire, preserve and make accessible research information and promote cost-effective, high-quality research through sharing research data and documentation. Some of the data sets that SADA holds and uses are those related to IK. In addition, the KMS Directorate is responsible for the development and maintenance of the 
South African Network Skills Abroad (SANSA) and the Committee of Data for Science and Technology (CODATA).

Through the work of the NRF therefore, it is possible to identify and develop hybrid solutions for IK management. It is possible to provide a broader context for interpreting and synthesising unstructured knowledge. This context is based on personal experiences and employs a variety of skills and capabilities or competencies as a frame of reference. Through the research funding that the NRF provides, researchers can identify key informants, for example an elderly woman who can explain how to design and make a traditional mat from long grass (lehlaka). Through the KMS of the NRF, and in conjunction with the UNESCO-MOST guidelines for best practices, technology can be used to capture, manipulate and distribute structured knowledge. Using the same example, this process could be explained step by step with labelled pictures. Therefore, both people and technology could complement one another in managing IK.

To illustrate this point further and also to show how the principle of knowledge sharing, using knowledge managers and applying ICT for knowledge management is applied, the case of the Campbell Collections at the University of Natal, as described by Peters (2001), would be most appropriate. The Campbell Collections have embarked on a programme of digital imaging of rare and fragile collections for preservation and access. The image collection represents the rich IK of the region, comprising antique and modern art, photographic prints, negatives, slides, transparencies and book illustrations. Museum documentation is also enriched with images of ethnographic objects, including Zulu pots, beadwork, carved sticks and items of traditional dress. The aims of the digitisation project are as follows:

- To allow broader access to the Collections for research purposes

- To provide improved tools for effective scholar-ship in associated metadata capture

- To protect the intellectual property of digital assets

- To license the use of images in a self-sustaining operation

The digitisation project at the Campbell Collections employs a three-tiered access system to protect the intellectual property that resides in these rare and often unique collections. The documentation of rich artefactual collections is enriched with a digital image of indigenous art, ethnographic objects and historic photographs. Low-resolution images are prepared in two sizes for presentation on the Web. This allows for identification of the subject matter and meets the expectation that "everything on the Web is free". Medium-resolution copies are made available to bona fide researchers at a minimal cost designed to cover expenses. Providing access to research resources is ultimately the Campbell Collections' objective. Copies of high-resolution archival master images are made available commercially on request, following a discreet investigation of the intended purpose, around which a business model has been constructed. The business model also protects intellectual property by employing a differentiated pricing structure for local and international clients. The pricing structure further differentiates between standard and educational publications, and single or multiple broadcasts in one country or worldwide.

In this way, the Campbell Collections aim to make their IK resources readily available locally for education and research. Peters (2001) points out that the Collections have taken cognisance of the fact that, through reformatting in a digital format, the cultural heritage of the South is made vulnerable to commercial exploitation by people in the North, thus reinforcing the digital divide. Instead, the Campbell Collections have taken advantage of the poor exchange rate of the South African rand to other currencies like the American dollar and pound sterling, to generate a market-related income to finance its ongoing digitisation programmes.

It is clear that a number of KM activities and initiatives are in place or are taking shape internationally, nationally (at least in South Africa) and even regionally. However, it is important to look at the local or community levels and ask the question: How applicable are KM principles in managing IK at the (indigenous) local community level? Related to this general question are specific questions like: To what extent is knowledge mapping, "recording", retention and sharing done in and among local communities? Are these KM processes as sophisticated at the local community level as those described in formal organisations and businesses? Should the KM processes for managing IK in fact be similar to business processes?

It is our view that some of the KM principles can be applied to manage certain aspects of IK. It is our further belief however, that owing to the nature of IK not all of it can (or should) be managed like scientific knowledge. We know, for example, that in local communities there are "knowers" of the IK who act as custodians. We know that in traditional communities, intellectual property is protected through trust and not necessarily through legal frameworks. Moreover, it is clear from the study of traditional societies that knowledge sharing and learning within 
communities proceed in a systematic and sophisticated manner, as Thakadu (1998) concludes. However, it is recognised that in the interaction of local or traditional communities with modern communities (and, in fact, the global community) there is a need to apply a number of principles for managing IK in order to preserve it, utilise it effectively and protect it. It is our view that these are the challenges we face and need to address if IK is to be managed effectively for the benefit of all. For instance, IK maps are essential for serving as guides to what type of knowledge is available and where it is available. Knowledge audits need to be conducted to enable structuring of knowledge, not only for better access but also for identification of ownership. However, we are also mindful that this would require many different skills and a great deal of interaction between traditional/local communities, the government and knowledge experts. Most importantly, there must be mutual trust and a working together for the common good among the stakeholders. Owners of intellectual property, whether individually or collectively, must be recognised and rewarded accordingly.

\section{Conclusion}

We have attempted to show in this paper that IK is extremely valuable and is increasingly becoming even more valuable to our communities. This is because the complex problems we are facing today require complex solutions that arise from the utilisation of all forms of knowledge, including IK. It seems to us that most KM principles can be used to manage IK. However, several issues need to be addressed for IK to be effectively managed for the benefit of all. The issue of ownership and responsibility for IK appears to be a very crucial one. The sharing of IK seems to exclude the indigenous communities themselves. The current international and national systems designed for managing IK seem to target the scientific community and persons at higher social and economic levels. The only access to IK systems that indigenous communities may have is through an intermediary who has access to these systems, such as a development expert, researcher, information professional or extension agent.

However, it is our view, and indeed one of the principles of KM, that the management of IK will follow a continuous cycle rather than being a one-off process. As people share and use knowledge, the categories of required knowledge will change according to individual needs. Culture develops and changes with time. Urban culture improves IK, as we have seen from the changes in fashion, for example. Traditional braids are back in fashion and men have joined women in having their hair braided. As people braid and share different styles, more new styles are created, including braiding dreadlocks. A great deal of knowledge, skill and talent goes into this aesthetic feature of IK. Furthermore, nutritionists for example, are increasingly recommending the consumption of natural rather than processed foods. We may well see the trend where people revert to traditional staple foods like mabela, fresh fruit and vegetables, rather than cooked and fried foods. Mapping knowledge should occur within a specified time range, otherwise the environment will be non-existent by the time the mapping process comes to an end. However, it should also be noted that IK is notoriously susceptible to abuse and exploitation. Appropriate intellectual property laws must accompany the use of IK.

\section{References}

Afolayan, A.J. 2001. Phytomedical research in the Eastern Cape. Paper read at the International Conference on Indigenous

Knowledge Systems: African Perspectives. University of Venda for Science and Technology, 12-15 September.

Allee, V. 1997. The knowledge evolution: expanding organizational intelligence. Boston: Butterworth-Heinemann.

Anderson Consulting. 2000. From librarian to knowledge manager: a natural evolution to meet the needs of a changing world. Paper presented at the SLIS/OSALL/SAOUG conference held at the Council for Scientific and Industrial Research, Pretoria, 11 October.

Anonymous. 2001. The San tribe to get medicine royalties. Sunday Tribune Business Report, 11 November, 1.

Barclay, R.O. \& Murray, P.C. 1997. What is knowledge management? [Online]. http://www.media-access.com/whatis.html Botha, M. \& Van Rooyen, L. 2000. Knowledge management. Meta-info Bulletin, 9(3): 28-36.

Corrall, S. 2001. Knowledge management: are we in the knowledge management business? Knowledge Management No. 18.

[Online]. http://www.ariadne.ac.uk/issue18/knowledge-mgt/

Davenport, T.H. 1998. Some principles of knowledge management. [Online]. http://www.bus.utexas.edu/kman $/ \mathrm{kmprin} . \mathrm{htm}$

Davenport, T.H. \& Prusak, L. 1998. Working knowledge: how organizations manage what they know. Boston, MA: Harvard Business School Press.

Editorial. 1993. Indigenous Knowledge and Development Monitor, 1(3): 1. 
Havelock, R.G. 1969. Introduction: dissemination and utilization (D\&U) as an emerging discipline, state of the art. In Havelock, R.G., Guskin, A., Frohman, M., Havelock, M., Hill, M. \& Huber, J., Planning for innovation through dissemination and utilization of knowledge. Institute of Social Research, University of Michigan. Ann Arbor, MI: Centre for Research on Utilization of Scientific Knowledge, 1-25.

Havelock, R.G., Guskin, A., Frohman, M., Havelock, M., Hill, M. \& Huber, J. 1969. Planning for innovation through dissemination and utilization of knowledge. Institute of Social Research, University of Michigan. Ann Arbor, MI: Centre for Research on Utilization of Scientific Knowledge, 1-25.

Kaniki, A.M. 1989. Agricultural information needs in Zambia: a two-way information flow. Ph.D. dissertation. Pittsburgh: University of Pittsburgh.

Kaniki, A.M. 2001. The use and abuse of information and the business ethics thereof. Paper presented at the SABINET Client's Conference, Fossil fuel - B2B (back to basics). Cathedral Peak Hotel, Drakensberg, South Africa, 30-31 August. [Online]. http://www.sabinet.co.za/conference/

Knowledge management glossary. 1998. [Online]. http://www.bus.utexas.edu/kman/glossary.htm

Maynard, J.T. 1978. Understanding chemical patents: a guide for inventors. Washington, DC: American Chemical Society.

Merali, Y. 1999. Self-organizing communities. In Reeves, J. (Ed.), Liberating knowledge: business guide. London: Caspian Publishing, 80-87.

National Research Foundation (NRF). n.d. Focus areas: indigenous knowledge systems. [Online]. http://www.nrf.ac.za/ focusareas/iks/

National Research Foundation (NRF). n.d. NRF profile. [Online]. http://www.nrf.ac.za/profile/

Nonaka, I. 1991. The knowledge creating company. Harvard Business Review, 69(6): 96-104.

Peters, D. 2001. The Campbell Collections digitization project. E-mail message to A.M. Kaniki, 13 November.

Probst, G., Raub, S. \& Romhardt, K. 1999. Managing knowledge: building blocks for success. Chichester, NY: John Wiley.

Quiroz, C. 1994. Biodiversity, indigenous knowledge, gender and intellectual property rights. Indigenous Knowledge and Development Monitor, Special Issue, 2(3): 12-15.

Snowden, D. 1999. Liberating knowledge. In Reeves, J. (Ed.), Liberating knowledge: business guide. London: Caspian Publishing, 6-19.

Spiegeler, I. 2001. Call for best practices on indigenous knowledge. E-mail message to A.M. Kaniki, 20 July.

Thakadu, O.T. 1998. Indigenous wildlife management knowledge systems and their role in facilitating community-based wildlife management projects in Botswana. Unpublished MSc (Environment and Development). Pietermaritzburg: University of Natal.

Warren, D.M. 1992. Centre for indigenous knowledge for agriculture and rural development. Ames, IA: Iowa State University. 